\title{
There is no anaerobic work capacity replenishment at critical power intensity: An indirect evidence ${ }^{\text {t }}$
}

\section{Il n'y a pas de restauration de la capacite de travail anaérobie à une intensité d'exercice correspondante à la puissance critique : une demonstration indirecte}

\author{
F.Y. Nakamura ${ }^{\mathrm{a}, *}$, G. Pereira $^{\mathrm{b}}$, D.W. Hill ${ }^{\mathrm{c}}$, S. Berthoin $^{\mathrm{d}}{ }^{\text {, E. Kokubun }}{ }^{\mathrm{b}}$ \\ ${ }^{a}$ Grupo de Estudo das Adaptações Fisiológicas ao Treinamento, Centro de Educação Física e Desportos, Universidade Estadual de Londrina, \\ Rod Celso Garcia Cid, km, 380, Campus Universitário. CEP: 86051-990, Londrina, Brazil \\ ${ }^{\mathrm{b}}$ Departamento de Educação Física, Universidade Estadual Paulista, Rio Claro, SP, Brazil \\ ${ }^{\mathrm{c}}$ Department of Kinesiology, Health Promotion and Recreation, University of North Texas, Denton, TX, USA \\ ${ }^{\mathrm{d}}$ Laboratory of Human Movement Studies (EA3608), Faculty of Sports Sciences and Physical Education, Lille 2 University, France
}

Received 22 June 2007; accepted 23 June 2007

Available online 2 June 2008

\begin{abstract}
Aim. - This study aimed to test if investigate whether the anaerobic work capacity is replenished while exercising at critical power intensity. Then, a known exercise duration, which demands high anaerobic energy contribution, was compared to intermittent exercise duration with passive and active (cycling at critical power intensity) rest periods.

Methods. - Nine participants performed five sessions of testing. From the 1 st to the 3 rd sessions, individuals cycled continuously at different workloads $\left(P_{\text {high }}, P_{\text {intermediate }}\right.$ and $\left.P_{\text {low }}\right)$ in order to estimate the critical power and the anaerobic work capacity. The 4 th and 5 th sessions were performed in order to determine the influence of anaerobic work capacity replenishment on exercise duration. They consisted of manipulating the resting type (passive or active) between two cycling efforts. The total exercise duration was determined by the sum of the two cycling efforts duration.

Results. - The exercise duration under passive resting condition $(408.0 \pm 42.0 \mathrm{~s})$ was longer $(p<0.05)$ than known exercise duration at $P_{\text {intermediate }}$ $\left(T_{\text {intermediate }}=305.8 \pm 30.5 \mathrm{~s}\right)$ and than exercise duration performed under active resting conditions $\left(T_{\text {active }}=304.4 \pm 30.7 \mathrm{~s}\right)$. However, there was no significant difference between $T_{\text {intermediate }}$ and $T_{\text {active }}$.

Conclusion. - These results demonstrated indirect evidence that the anaerobic work capacity is not replenished while exercising at critical power intensity.

(C) 2008 Elsevier Masson SAS. All rights reserved.

\section{Résumé}

Objectif. - L'objectif de cette étude est d'examiner si la capacité de travail anaérobie est restaurée lors d'un exercice réalisé à puissance critique. Pour cela, un exercice de durée connue, qui sollicite à un haut niveau la filière anaérobie a été comparé à un exercice intermittent réalisé soit suivant une modalité de récupération passive, soit suivant une modalité de récupération active (à puissance critique).

Méthodes. - Neuf sujets ont participé à cinq sessions de tests. Lors des sessions un à trois, des exercices continus sur ergocycle étaient réalisés à trois puissances différentes $\left(P_{\text {élevée }}, P_{\text {intermdiaire }}\right.$ et $\left.P_{\text {faible }}\right)$, afin de déterminer la puissance critique et la capacité de travail anaérobie. Les sessions quatre et cinq étaient réalisées dans un ordre aléatoire pour identifier l'influence de la restauration de la capacité de travail anaérobie sur le temps d'exercice. Elles se différenciaient suivant l'intensité de la récupération (passive ou active) et consistaient en un exercice de 150 secondes à

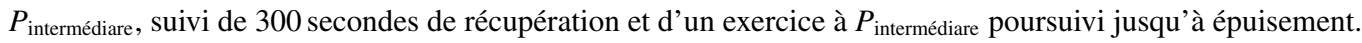

\footnotetext{
is Presented at the symposium "Puissance critique", Lille, France, 22nd and 23rd of June, 2007.

* Corresponding author.

E-mail address: fabioy_nakamura@yahoo.com.br (F.Y. Nakamura).
} 
Résultats. - Dans de la condition de récupération passive ( $T_{\text {passive }}=408,0 \pm 42,0$ secondes), la durée d'exercice était plus longue $(p<0,05)$ que lors de l'exercice à $P_{\text {intermédiare }}\left(T_{\text {intermédiare }}=305,8 \pm 42,0\right.$ secondes $)$ et lors de l'exercice réalisé avec une récupération active ( $T_{\text {active }}=304,4 \pm 30,5$ secondes). Il n'y avait pas de différence significative entre $T_{\text {intermédiaire }}$ et $T_{\text {active }}$.

Conclusion. - Ces résultats montrent de façon indirecte que la capacité de travail anaérobie n'est pas restaurée lors d'un exercice réalisé à puissance critique.

(C) 2008 Elsevier Masson SAS. All rights reserved.

Keywords: Cycling; Critical power; Exhaustion time

Mots clés : Cyclisme ; Puissance critique ; Temps limite d'exercice

\section{Introduction}

Constant-load cycling, running or swimming have been shown a hyperbolic function between the power (or velocity) and the tolerable duration of the exercise $[10,12,15]$. Such power-duration relationship has a power asymptote termed critical power (CP), whilst the constant curvature of the hyperbola is termed anaerobic work capacity (AWC). Theoretically, CP can be sustained for a long time using aerobic metabolism [7] and AWC represents the fixed maximal amount of work that can be performed at the expense of oxygen and anaerobic energy stored (i.e., high energy phosphates and a source related to anaerobic glycolysis) [8,11].

The $\mathrm{CP}$ is the highest power output which elicits pulmonary oxygen uptake $\left(V_{\mathrm{O}_{2}}\right)$ and blood lactate concentration steadystate $[9,13]$. It represents the uppermost intensity in the heavy intensity domain [6]. Exercise intensities performed below or at $\mathrm{CP}$ elicits markedly distinct physiological responses from those observed at intensities above CP, i.e., within the severe intensity domain. During severe exercise intensity, there is a gradual rise of $V_{\mathrm{O}_{2}}$ to its maximum value and a continuous increase in blood lactate concentration for the duration of exercise until exhaustion occurs [6]. Therefore, exhaustion is suggested to coincide with the complete utilisation of the anaerobic reserves when exercising within the severe domain $[1,5]$.

Exercises performed below or at $\mathrm{CP}$ intensity can be sustained for longer with no anaerobic energy reserve depletion $[9,13]$. Also, when exercising below $\mathrm{CP}$ intensity, the anaerobic energy reserve is replenished [4]. However, it is not known whether anaerobic energy reserve is replenished, at least partially, exercising at $\mathrm{CP}$ intensity. Since CP demarcates the transition threshold between heavy and severe intensity domains, it is hypothesized that $\mathrm{CP}$ is a neutral intensity, wherein there is neither anaerobic energy reserve depletion nor anaerobic energy reserve replenishment. Then, an experimental design can be elaborated in order to test such questioning. A possibility is using intermittent exercise which demands anaerobic energy and comparing the influence of resting types known exercise duration. For instance, following non-exhaustive exercise performed above $\mathrm{CP}$ intensity that induces partial anaerobic energy depletion, active rest involving exercise at $\mathrm{CP}$ intensity would not change the known exercise duration in the subsequent test (which also demands anaerobic energy), since it would not have anaerobic energy replenishment during the rest. Contrary to such expectation, following non-exhaustive exercise performed above $\mathrm{CP}$ intensity, passive rest would allow replenishment of at least a portion of the depleted anaerobic energy which would increase the known exercise duration in the subsequent test due to anaerobic energy replenishment. Differences on exercise durations, which demands anaerobic energy, can be interpreted as an indirect evidence that AWC is replenished exercising at $\mathrm{CP}$ intensity. Therefore, this study aimed to test if the AWC is replenished exercising at CP intensity. It was hypothesized that AWC is not replenished exercising at CP.

\section{Methods}

\subsection{Participants}

Nine healthy physically active individuals (two women: 19 and 20 years; 157 and $167 \mathrm{~cm} ; 48$ and $58 \mathrm{~kg}$; and seven men: $21.6 \pm 2.4$ years; $177.0 \pm 5.2 \mathrm{~cm} ; 67.7 \pm 4.3 \mathrm{~kg}$ ) participated in this study. Participants were asked to refrain from severe physical activity 12 hours before each test. This study was approved by the local research Ethics Committee and participants were informed about the procedures and risks before giving written consent.

\subsection{Experimental design}

Participants performed five sessions of test on different days. From the 1 st to the 3 rd sessions, individuals cycled continuously at different workloads in order to estimate the $\mathrm{CP}$ and the AWC. The 4th and the 5th sessions were performed in order to determine the influence of AWC replenishment on exercise duration. They consisted of manipulating the resting type (passive or active) between two cycling (supra-CP) efforts.

\subsection{Determination of $C P$ and $A W C$}

Participants warmed-up on cycle ergometer (Monark, Varberg, Sweden) during five minutes at $75 \mathrm{~W}$. Afterwards, they cycled at three different fixed power outputs $\left(P_{\text {high }}=326.0 \pm 109.7 \mathrm{~W} ; \quad P_{\text {intermediate }}=239.0 \pm 62.4 \mathrm{~W} ; \quad\right.$ and $P_{\text {low }}=213.7 \pm 55.3 \mathrm{~W}$ ), selected individually, in order to exhaust approximately within 2, 5 and $10 \mathrm{~min}$ [1]. Pedal cadence was maintained at $75 \mathrm{rpm}$ throughout the exercise. Exhaustion was characterized when participants could no longer sustain such rpm during five seconds, despite verbal encouragement. From each participant's test, the power output $(P$, 


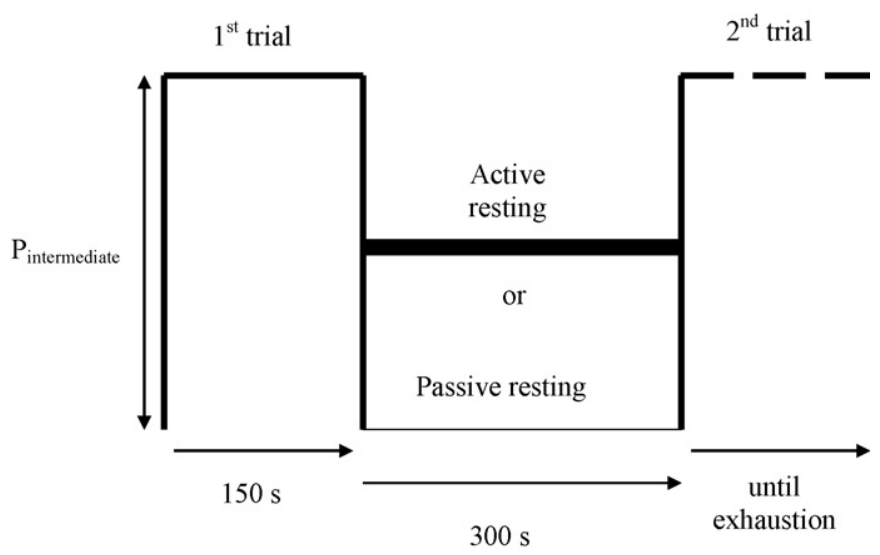

Fig. 1. Schematic diagram of intermittent exercises, performed at specific power output $\left(\mathrm{P}_{\text {intermediate }}\right)$, manipulating the rest period between two trials. The active resting consisted of cycling at critical power intensity.

watts) and time to exhaustion ( $T$, seconds) were used to calculate the $\mathrm{CP}$ and $\mathrm{AWC}$ through nonlinear power-time equation $(T=\mathrm{AWC} /[P-\mathrm{CP}])$ proposed by Monod and Scherrer [11].

\subsection{Influence of $A W C$ replenishment on exercise duration}

After warming-up, participants cycled at their $P_{\text {intermediate }}$ during $150 \mathrm{~s}$ (1st trial). Afterwards, they rested $300 \mathrm{~s}$ either passively or actively. The latter consisted of cycling at CP intensity. Thereafter, participants cycled once more at $P_{\text {intermediate }}$ until exhaustion (2nd trial) (Fig. 1). Then, $T_{\text {intermediate }}$ (exercise duration determined during the session to estimate $\mathrm{CP}$ and AWC, i.e., $T_{\text {intermediate }} \approx 300 \mathrm{~s}$ ), $T_{\text {active }}$ ( 1 st added to 2 nd trial duration, separated by active resting), and $T_{\text {passive }}$ ( $1 \mathrm{st}$ added to 2nd trial duration, separated by passive resting) were used to compare the effects of AWC replenishment on exercise duration.

\subsection{Statistics}

Power analysis revealed that the number of participants for time to exhaustion produced power value of 1.0. After normality assurance, the exercise durations ( $T_{\text {intermediate }}, T_{\text {active }}$, and $T_{\text {passive }}$ ) were compared using ANOVA for repeated measures, followed by Scheffé's test. The significance level was set at $p<0.05$. Data are presented as mean \pm S.D.

\section{Results}

The mean time to exhaustion at $P_{\text {high }}, P_{\text {intermediate, }}$ and $P_{\text {low }}$ were $129.1 \pm 29.0,305.8 \pm 30.5$ and $590.8 \pm 141.8 \mathrm{~s}$, respectively. The $\mathrm{CP}(184 \pm 49 \mathrm{~W})$ and $\mathrm{AWC}(16,6 \pm 4,4 \mathrm{~J})$ parameters had low standard error estimate $(\mathrm{CP}=2.9 \pm 1.4 \mathrm{~W}$; $\mathrm{AWC}=1,5 \pm 0,6 \mathrm{~J})$ and high coefficient of determination $(0.99 \pm 0.01)$. The $T_{\text {passive }}(408.0 \pm 42.0 \mathrm{~s})$ was longer $(p<0.05)$ than $T_{\text {intermediate }}(305.8 \pm 30.5 \mathrm{~s})$ and $T_{\text {active }}(304.4 \pm 30.7 \mathrm{~s})$. However, there was no difference $(p>0.05)$ between $T_{\text {intermediate }}$ and $T_{\text {active }}$ (Fig. 2).

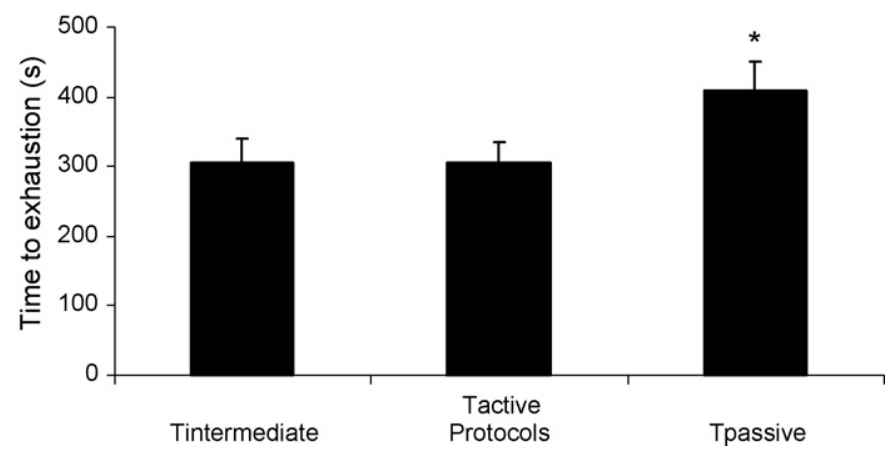

Fig. 2. Mean and Standard Deviation of time to exhaustion of different exercise protocols. ${ }^{*}$ Different from $\mathrm{T}_{\text {intermediate }}$ and $\mathrm{T}_{\text {active }}(p<0.05)$.

\section{Discussion}

This study aimed to investigate whether the AWC is replenished exercising at $\mathrm{CP}$ intensity. Then, a known exercise duration, which demands high anaerobic energy contribution, was compared to intermittent exercise duration with passive and active (cycling at $\mathrm{CP}$ intensity) rest periods. It was found that $T_{\text {intermediate }}$ and $T_{\text {active }}$ did not differ from and they were shorter than $T_{\text {passive. }}$ These results demonstrated indirect evidence that the AWC is not replenished exercising at $\mathrm{CP}$ intensity.

The anaerobic energy utilization throughout the exercises ( $T_{\text {intermediate }}, T_{\text {active }}, T_{\text {passive }}$ ) can be quantified in order to explain the longer exercise duration after passive resting. Since we have known the time to exhaustion, the power output and the critical power for each participant, the AWC utilised can be determined by: $\mathrm{AWC}=T \times(P-\mathrm{CP})$. To determine the AWC utilised for each exercise it must replace the time to exhaustion with its respective exercise duration (i.e., $T_{\text {intermediate, }} T_{\text {active, }}$, $\left.T_{\text {passive }}\right)$. Based on such calculations, we observed similar anaerobic energy utilization between $T_{\text {intermediate }}(16.6 \pm 4.4 \mathrm{~J})$ and $T_{\text {active }}(16.8 \pm 5.2 \mathrm{~J})$. However, $T_{\text {passive }}(22.4 \pm 6.3 \mathrm{~J})$ was greater than $T_{\text {intermediate }}$ and $T_{\text {active }}$. The greater amount of anaerobic energy utilization during the exercise protocol with passive rest ( $\sim 35 \%$ greater than the other exercises) may explain why the exercise duration was longer. It means that during passive resting there was a partial replenishment of the anaerobic reserve, which can be related to the replenishment of the high energy phosphates and a source related to anaerobic glycolysis $[2,3,14]$.

The influence of exercise intensity domains upon depletion/replenishment of AWC and exercise duration has been approached previously [4,5]). Fukuba and Whipp [5] suggested that the physiological underpinnings of the concept of critical power are valid and remain so even during and after a fatiguing bout of exercise, i.e., once the AWC is depleted, exercise cannot continue unless the work rate is reduced into a domain where "wholly aerobic" energy transfer may allow exercise to be sustained. Accordingly, Coats et al. [4] suggest that anaerobic energy reserve is replenished only at sub$\mathrm{CP}$ work rate. Our results agreed with these studies, due to during passive resting the anaerobic energy reserve was replen- 
ished and induced longer exercise duration upon subsequent trial.

Moreover, the similarities between $T_{\text {intermediate }}$ and $T_{\text {active }}$, and between anaerobic energy utilizations indicate that exercising at $\mathrm{CP}$ intensity the AWC is not replenished. This finding represents an enhancement of the critical power concept, although future studies with physiological measurements have to be performed to further confirmation of such findings. Considering our results, the physiological meaning of the $\mathrm{CP}$ may be interpreted as the exercise intensity at which AWC is neither depleted nor replenished. In a practical sense (similar to Coasts et al., [4] and Fukuba and Whipp [5]), this suggests that an athlete who performs a pace strategy depleting AWC before the end of the race must not only reduce their work rate to continue exercise but also to reduce it to a sub-CP level. However, an experimental approach should be elaborated to test the relations among the pace strategy, CP and AWC.

\section{Conclusion}

The present study showed that the passive and active rest periods between two supra-CP efforts, which demands high anaerobic energy contribution, influenced on known exercise duration. It was assumed that partial replenishment of AWC allowed participants to increase their exercise duration in such efforts. Therefore, it is suggested that AWC is not replenished while exercising at $\mathrm{CP}$ intensity.

\section{Acknowledgements}

Dr. Nakamura was supported by fellowship from CAPES. Dr. Kokubun was supported by fellowship number 351049/1992-4 from CNPq.

\section{References}

[1] Bishop D, Jenkins DG, Howard A. The critical power function is dependent on the duration of the predictive exercise tests chosen. Int J Sports Med 1998;19:125-9.

[2] Bogdanis GC, Nevill ME, Bobbis LH, Lakomy HKA, Nevill AM. Recovery of power output and muscle metabolites following $30 \mathrm{~s}$ of maximal sprint cycling in man. J Physiol 1995;482:467-80.

[3] Bogdanis GC, Nevill ME, Lakomy HKA, Graham CM, Louis G. Effects of active recovery on power output during repeated maximal sprint cycling. Eur J Appl Physiol 1996;74:461-9.

[4] Coats EM, Rossiter HB, Day JR, Miura A, Fukuba Y, Whipp BJ. Intensedependent tolerance to exercise after attaining $V_{\mathrm{O}_{2} \text { max }}$ in humans. J Appl Physiol 2003;95:483-90.

[5] Fukuba Y, Whipp BJ. A metabolic limit on the ability to make up for lost time in endurance events. J Appl Physiol 1999;87:853-61.

[6] Gaesser GA, Poole D. The slow component of oxygen uptake kinetics in humans. Exerc Sport Sci Rev 1996;24:35-70.

[7] Hill DW. The critical power concept. Sports Med 1993;16:237-54.

[8] Hill DW, Smith JC. A method to ensure the accuracy of estimates of anaerobic capacity derived using the critical power concept. J Sports Med Phys Fitness 1994;34:23-37.

[9] Hill DW, Smith JC. Determination of critical power by pulmonary gas exchange. Can J Appl Physiol 1999;24:74-86.

[10] Hughson RL, Orok CJ, Staudt LE. A high velocity treadmill running test to asses endurance running potential. Int J Sports Med 1984;5:23-5.

[11] Monod H, Scherrer J. The work capacity of a synergic muscular group. Ergonomics 1965;8:329-38.

[12] Moritani T, Nagata A, deVries HA, Muro M. Critical power as a measure of physical work capacity and anaerobic threshold. Ergonomics 1981;24:339-50.

[13] Poole DC, Ward SA, Gardner GW, Whipp BJ. Metabolic and respiratory profile of the upper limit for prolonged exercise in man. Ergonomics 1988;31:1265-79.

[14] Stamford BA, Weltman A, Moffat R, Sady S. Exercise recovery above and below anaerobic threshold following maximal work. J Appl Physiol 1981;51:840-4.

[15] Wakayoshi K, Ikuta K, Yoshida T, Udo M, Moritani T, Mutoh Y, et al. Determination and validity of critical velocity as an index of swimming performance in the competitive swimmer. Eur J Appl Physiol 1992;64:153-7. 